\title{
A CONSTRUÇÃO DO BRASIL: PROJETOS DE INTEGRAÇÃO DA AMÉRICA PORTUGUESA
}

\author{
Cláudia Maria das Graças Chaves \\ Doutora em História - Universidade Federal Fluminense
}

\section{Resumo}

Este artigo analisa os principais projetos de integração territorial abertura de rios navegáveis e de estradas - propostos para o Brasil entre o final do século XVIII e o início do século XIX. Parte dos projetos foram implementados, outros tornaram-se não realizados, mas acabaram por representar uma nova percepção da realidade.

\section{Abstract}

This article analyses the main projects of territorial integration opening of navigable rivers and of highways - proposed to Brazil between the end of the XVIII ${ }^{\text {th }}$ century and the beginning of the XIX ${ }^{\text {th }}$. Some of these projects were implemented, others were not accomplished. Even so they represent a new perception of reality.

\section{Pallavras-Chave}

Império Luso-Brasileiro $\bullet$ Mercados $\bullet$ Reformismo Ilustrado $\bullet$ Fronteiras

\section{Keywords}

Portuguese-Brazilian Empire $\bullet$ Markets $\bullet$ Enlightened Reformism $\bullet$ Frontiers 
E ntre os "Projetos" das reformas ilustradas e dos "melhoramentos" para a América portuguesa, destacava-se a necessidade de ampliar o conhecimento sobre o território e sua população. Nesse sentido, abrir estradas e canais navegáveis tornou-se o ponto de partida para “descobrir” a Colônia. Não só “descobrir”, mas também integrá-la, o que poderíamos chamar de um princípio da "interiorização da metrópole", ou, como disse Capistrano de Abreu, tornar intrínseco o centro que se encontrava alémmar. Assim se consolidava o Império luso-brasileiro.

Além das providências que já se tomavam, desde o final do século XVIII, no sentido de conhecer e melhorar os caminhos que interligavam as capitanias brasileiras, como eram os casos do caminho que interligava Minas ao Rio de Janeiro e das expedições aos rios navegáveis, a chegada da Família Real ao Brasil deu novo vigor a tais providências. Em 1808, o Príncipe Regente, para centralizar as informações militares sobre o território brasileiro determina a criação de um arquivo central em que se depositasse todo o acervo resultante das expedições que haviam sido feitas e das que estavam em curso . Segundo D. Rodrigo de Sousa Coutinho, os engenheiros encarregados de recolher e arquivar todos os mapas, os projetos e os relatos geográficos do Brasil - incluindo todos os projetos de estradas, navegação de rios, canais, portos e regiões limítrofes - deveriam analisá-los para a "maior extensão de agricultura, comércio e artes" ${ }^{2}$.

A quantidade de rios freqüentemente caudalosos era sempre uma possibilidade de barateamento de transportes além de encurtadores de caminhos, mas também constituíam um obstáculo a ser vencido, pois nem sempre eram navegáveis e possuíam muitas cachoeiras. Os rios Paraíba, Paraibuna, Grande, Doce, Jequitinhonha, Mucuri, Pardo, São Francisco, Rio das Velhas eram os principais canais fluviais que cortavam a Capitania de Minas Gerais e a interligavam às demais capitanias. Por eles, era possível comunicar-se com o Rio de Janeiro, Goiás, Mato Grosso,

\footnotetext{
${ }^{1}$ Biblioteca Nacional de Lisboa, Correio Braziliense, seção de periódicos, rolo 1724, fl. 441-5.

${ }^{2}$ Biblioteca Nacional de Lisboa, Correio Braziliense, seção de periódicos, rolo 1724, fl. 441-5.
} 
Espírito Santo, São Paulo e Bahia. No início do processo de interiorização do território pelos bandeirantes, eles eram, principalmente, obstáculos. Desconhecidos e arriscados, os rios não eram explorados, sendo os caminhos por terra preferidos pelos primeiros bandeirantes.

Segundo Sérgio B. de Holanda (1957: 162), naqueles tempos as embarcações eram geralmente simples canoas de casca ou toscas jangadas, construídas apenas para trechos em que a marcha a pé tornava-se impossível. Entretanto, à medida que se consolidavam as conquistas, desenvolviam-se as navegações. Para o autor, no século XVIII, as técnicas de navegação foram aprimoradas, criando não apenas uma maior utilidade para o comércio, mas também servindo como forma de integração do território e propiciadora da unidade nacional, a despeito das ações isoladas, aventureiras e nem sempre bem sucedidas dos primeiros desbravadores.

Em Minas Gerais, durante todo o século XVIII, o temor do contrabando do ouro e as precárias condições de fiscalização foram os maiores empecilhos para que não se desenvolvessem as melhores vias de comunicação das terras centrais com as regiões litorâneas, sobretudo as vias fluviais, tanto mais difíceis de serem controladas. No final do século, no entanto, essa situação começava a mudar.

O primeiro alvo, evidentemente, é o caminho para o Rio de Janeiro. Melhorálo e ampliá-lo é a primeira das providências que tomará força a partir de 1808, quando da criação da Junta do Comércio, Agricultura, Fábricas e Navegação. Em 1799, o Porto Estrela, entre a Serra da Boa Vista e o Registro da Paraibuna, tornou-se motivo de constantes pedidos para a melhoria dos caminhos entre Minas Gerais e Rio de Janeiro. Diziam os pedidos que os moradores da região lamentavam a dificuldade do caminho, pois eram "obrigados a viverem somente da plantação de milho, com que apenas suprem as tropas pela impossibilidade (...) de exportarem os seus efeitos" compostos de algodão, café e açúcar ${ }^{3}$. Propunham a utilização da arrematação dos

\footnotetext{
${ }^{3}$ Avulsos da Seção Colonial, doc. 63, Arquivo Público Mineiro (APM). Ver também: ACC, Pl. 19514, rolo 508, APM. Ver também: AHU, documentos referentes ao Rio de Janeiro, Caixa 185 doc. 17; AHU, Rio de Janeiro, Caixa 236 doc. 16; AHU, Códice 2109, fl. 202.
} 
direitos de entrada, assim como uma contribuição adicional dos moradores e comerciantes da região para a abertura e conservação da estrada e mais a contribuição de madeiras específicas, que eram perobas e tapinhoãs, para a construção de canoas ${ }^{4}$.

Não só se torna necessário melhorar o caminho antigo que ligava Vila Rica ao Rio de Janeiro como também se torna necessário criar condições para encurtar o caminho para Cantagalo e Campos dos Goitacazes, na Capitania do Rio de Janeiro, sem a utilização da antiga estrada "Garcia Rodrigues". O recurso seria melhorar as condições de navegação do Paraíba do Sul, rompendo o monopólio dos fazendeiros da referida estrada e destinando destacamentos para conter o gentio da região do Rio Pomba ${ }^{5}$. A preocupação com a redução dos custos do transporte de gêneros para os Campos dos Goitacazes e Cantagalo parece ter dado resultado, pois são estas duas regiões extremamente freqüentadas nas primeiras décadas do século XIX por comerciantes mineiros, justamente pelo Registro do Rio Pomba.

Os vínculos criados entre as regiões de Minas com Cantagalo podem ser verificados através do plano de desenvolvimento de comércio e produção para as duas regiões, enviado ao Desembargador Procurador da Fazenda, em 1808, pelo Conselheiro Beltrão de Gouveia de Almeida ${ }^{6}$. Para Beltrão, o Vice-Rei do Brasil no ano de 1786, Luis de Vasconcelos e Souza, soube aproveitar as denúncias de garimpeiros "ilegais" na região de Cantagalo para incentivar a agricultura na região. Para tanto, o Vice-Rei teria convocado particulares que nada sabiam, ou entendiam de mineração para a empreitada, em que foi prontamente atendido, sendo dividida, a partir daí, a região em dois vales. Não sendo mineiros e "ignorando os métodos da extração do

\footnotetext{
${ }^{4}$ Segundo Sérgio B. de Holanda, a técnica da navegação fluvial adotada durante este período conservava intacta a tradição indígena para o fabrico das canoas, sendo nula a contribuição européia. "Embarcações monóxilas, isto é, feitas de lenho inteiriço, adotam-se geralmente. É natural que se preferissem estas por mais duráveis e resistentes, às simples canoas de casca, também de procedência indígena e de que se serviram os primeiros bandeirantes. Para a sua confecção, empregaram-se madeiras determinadas, como a da peroba e a ximbaúva, devido não só ao diâmetro relativamente grande que podem atingir, como ao fato de suportarem bem a umidade". (Holanda 1957: 171). ${ }^{5}$ Avulsos da Seção colonial, doc 64, APM.

${ }^{6}$ Arquivo Histórico Ultramarino, documentos referentes ao Rio de Janeiro, caixa 241, doc. 31.
} 
ouro", os agricultores "se contentaram com o que podia produzir as terras à superfície", criando o povoado de Cantagalo a partir de 28 casas unidas. No ano de 1802, segundo Beltrão, o povoado já contava com 869 pessoas, as quais erigiram a paróquia do Santíssimo Sacramento do Cantagalo. Tanta prosperidade, no entanto, não resistiu à "frouxidão" do Conde de Resende, o qual acabou por atrair novamente para a região mineradores interessados na fácil riqueza. Com isso, levava para esta região "os habitantes de Minas Gerais pela perícia destes para a mineração, expertos na cultura e escavação nos lugares próprios”. Segundo o plano de Beltrão, era necessário reverter aquele processo, conjugando a produção de Cantagalo à de Goitacazes e de Minas Gerais. Para tanto, seria necessária a abertura de novas estradas que interligassem essas regiões, o que efetivamente foi feito. Segundo o Conselheiro, os resultados de tal empreendimento renderiam muito mais à Real Fazenda do que a busca insana pelo ouro, porque:

"A fertilidade deste terreno do sertão de Cantagalo é tão pasmosa que se tem visto produzir a semente de um alqueire de milho, duzentos alqueires. A propriedade que ele tem para a cultura do feijão, café, mandioca, fumo, anil e cana de açúcar são tal que muitos desejam sub rogar as suas possessões com as das vizinhanças de Cantagalo. E será louvável que o Conde de Resende gravasse o público e o Estado no total abandono deste terreno. É muito pelo contrário só repreensível semelhante abandono, pois que sobejava, que ele tendo conhecimentos topográficos, de que se olvidou, sabendo dos grandes rios aurígeros que cercam o mesmo sertão, Rio Negro e Rio Grande, se a estes aplicasse as forças e providências régias, de que estava munido, fizesse as exportações, que tanto se tem carecido, aumentava-se a população convocando os desejosos locais, fizesse crescer a criação de gados, que nele pasmosamente multiplicam e engordam com famosa admiração (...)."

Se as condições de transporte eram difíceis na região sul e sudeste da Capitania mineira, tanto mais difícil era para as comarcas de dentro e do norte de Minas Gerais. Para esta região, a navegação pelo Rio Doce passou a ser incentivada como uma alternativa ao transporte por terra de gêneros que se destinariam ao Rio de Janeiro. O transporte por terra não só encareceria o produto a ser comercializado, tornando- 
o menos competitivo, como desestimularia a produção dessas regiões. Não faltaram sugestões de novos caminhos, sobretudo fluviais, para estimular o comércio de Minas com o Espírito Santo e Bahia. Curiosamente, a maior defesa desses novos caminhos vinha, principalmente, da Bahia e Espírito Santo, para as quais era fundamental estabelecer um comércio regular para as produções mineiras.

A execução do projeto do Rio Doce era constantemente ameaçada por ser onerosa e arriscada, apesar de ter surgido logo nos finais do século XVIII e ter ganho maior consistência no início do século XIX com a criação de uma Companhia formada por acionistas, tendo sido criado até mesmo um estatuto para o seu funcionamento.

Em meio a esse processo, surgiu a proposta alternativa de criação do canal do Rio Mucuri. Antônio de Araújo do Conselho do Estado lembrava, em 1812, que eram três as prováveis aberturas de Minas Gerais para a costa marítima: Ilhéus, Jequitinhonha e Rio Doce. Entretanto, a primeira era muito distante e as outras difíceis e impunham grandes percursos por terra. Já o Rio Mucuri, que partia da Comarca de Porto Seguro em direção a Minas Novas, em Minas Gerais, era considerado mais curto e melhor. Essa proposta é feita a partir de informações dadas por exploradores que haviam feito expedições à foz do Rio Mucuri.

O Conselheiro Antônio de Araújo lembrava que não havia muitos mapas precisos das vastas regiões desconhecidas e que, para se abrirem estradas, era necessário "verificar primeiro, por meio de observações astronômicas, as posições geográficas dos dois lugares entre os quais se pretendia estabelecer comunicação, dirigindo a abertura pelos rumos da agulha" ${ }^{8}$. Depois, ele próprio diz que, mesmo não havendo estudos astronômicos, o que importava na realidade era saber qual o caminho mais curto entre dois pontos, descontados, é claro, os rodeios que se tinha que fazer num país com tantos montes e inundações. Entretanto, seguindo sempre o mesmo rumo do Rio Mucuri, seria ainda possível, nos momentos em que precisassem passar por

\footnotetext{
${ }^{7}$ Idem.

${ }^{8}$ Seção Colonial 354, fl.345, APM.
} 
terra, perdê-lo de vista ${ }^{9}$. De qualquer maneira, era necessário abrir estradas, explorar as regiões inóspitas e desconhecidas para expandir a produção e o abastecimento interno da Bahia e do Rio de Janeiro, principalmente, “depois do aumento da sua população" $"$. Falando sobre os sertões do leste, Antônio de Araújo diz que:

Daqui para adiante é o país uma incógnita, mas sabe-se que por toda parte há gentios mais ou menos ferozes. Os botocudos divagam pelos desertos, entre o Rio Doce e o Jequitinhonha. Por isto se faz preciso, que os exploradores vão armados e em número bastante para resistir e afugentar aqueles bárbaros, os quais não serão jamais domados, sem que aqueles imensos ermos sejam cortados por estradas que se povoem ${ }^{11}$.

Domar os índios e estabelecer produções à beira do rio era uma tarefa não só "civilizatória", mas também garantia das muitas culturas e extrações que se poderiam fazer naquela região. Entre os gêneros citados como necessários e que eram produzidos com fartura por Minas Gerais, estão: café, açúcar, salitre, algodão, milho, feijão, mandioca e carne de porco. Coloca-se especial ênfase no algodão de Minas Novas ${ }^{12}$.

O Rio Pardo, assim como o Mucuri e Jequitinhonha, era uma das opções de comunicação desta mesma região de Minas com o sul da Bahia. Em 1806, foi organizada uma expedição por João Gonçalves da Costa. Ele relatou suas aventuras na Gazeta da Bahia em 1817, para que todos tivessem conhecimento das riquezas

\footnotetext{
${ }^{9}$ Sérgio B. de Holanda chama a atenção para esse detalhe. Nem sempre era possível percorrer todo o percurso no rio. "Em certos lugares a tripulação era forçada a passar por terra, arrastando as canoas ou guindando-as com cordas, no que se gastava muito tempo e trabalho. Em cachoeiras médias ou menores, não saíam os barcos do rio, embora fosse preciso alivia-los das cargas e dos passageiros" (1957:173).

${ }^{10}$ Seção Colonial 354, fl.345, APM.

${ }^{11}$ Seção Colonial 354, fl.345, APM.

${ }^{12}$ Segundo Waldemar de Almeida Barbosa (1995:349), Teófilo Ottoni, fundador da cidade que hoje tem o seu nome, antiga Filadélfia, alimentava, desde 1847, o plano de ligar o nordeste mineiro ao litoral e "civilizar" os índios. Criou a Companhia do Mucuri em 1851 e organizou duas expedições para conhecer o Rio. Estranho é o fato de o autor não citar os projetos anteriores de abertura do canal, colocando Teófilo Ottoni como autor da idéia.
} 
daquele canal que ligava Ilhéus ao Norte de Minas e que, portanto, quisessem investir seus cabedais em tal empreendimento ${ }^{13}$. Esse relato impressionou o correspondente Hipólito José da Costa do Correio Braziliense, que em sua coluna "Melhoramentos no Brazil", cita as utilidades da navegação entre Minas e Bahia e elogia todas as providências tomadas nesse sentido ${ }^{14}$. No ano seguinte, o Correio publica uma correspondência do Governador da Bahia ao Conde de Palma, de setembro de 1818, sobre as providências de se abrir os canais. Depois de detalhar as inúmeras providências que já haviam sido tomadas da parte de Minas para povoar as margens dos rios Pardo, Jequitinhonha e Salça, sugere, ainda, a construção de armazéns para os negociantes das praças da Vila de Belmonte e de todos os outros interessados das Comarcas de Ilhéus e Porto Seguro. Para o Governador da Bahia, era necessário aproximar "com a força moral as distâncias que a força física separou" para que aquela Capitania se tornasse tão rica quanto era a do Rio de Janeiro ${ }^{15}$.

Ainda no ano de 1819, na coluna "Melhoramentos no Brazil", do Correio Braziliense, são publicados os informes dos comandantes dos destacamentos de colonização dos rios Pardo, Salça e Jequitinhonha. Segundo esses informes são grandes as remessas de algodão de Minas Novas para a Bahia, sobretudo pelo Porto das Canavieiras, onde desemboca o Rio Salça, considerado de menor risco.

Canavieiras deve pois ser para o Jequitinhonha, e Salça o mesmo que é a Cachoeira para o Rio das Contas e Campos; (...). Que ajuizada especulação para um negociante empreendedor. Foi com semelhantes especulações que enriqueceram muitos principiantes, no começo das Vilas desta Capitania, e daí vieram grandes casas de que ainda há memória. Naqueles pontos podemos dizer que o Brasil ainda agora se descobre; e todos sabem que nos descobrimentos das coisas se fazem grandes fortunas. $O$ algodão é hoje o ramo mais favorito da lavoura,

\footnotetext{
${ }^{13}$ A Memória sobre a conquista do Rio Pardo foi publicada nos dias 14, 21 e 28 de julho de 1817 na Gazeta da Bahia e no ano seguinte no Correio Braziliense, Biblioteca Nacional de Lisboa (BNL), rolo 1738 , fl,. 460-2.

${ }^{14}$ Correio Braziliense, BNL, rolo 1738, fl,. 460-2.

${ }^{15}$ BNL, seção de periódicos, Correio Braziliense, 1819, rolo 1738, fls. 285-8.
} 
e do comércio do Brasil, e todo o terreno que vai de Canavieiras até Minas é o mais próprio para esta cultura (itálicos meus) ${ }^{16}$.

É interessante notar, pelo documento acima citado, a idéia de Brasil que se descobre pelas vias internas e que se aventura na descoberta de novas rotas para aumentar o fluxo de escoamento de um produto que se transformara no favorito para as exportações. $\mathrm{O}$ autor deixa bem claro que para os "gêneros de primeira necessidade" já se haviam estabelecido as rotas "de um grande comércio interior" que comunicava Minas com a Bahia. Tratava-se, naquele momento, de um produto especial, que se destinava, principalmente, à exportação.

A região Nordeste de Minas contava, portanto, com vastas possibilidades de abrir caminho para o mar, em direção à Bahia ou ao Espírito Santo, através de seus canais fluviais. Não faltaram propostas e até mesmo efetivas experiências com a formação de colônias e destacamentos militares, mas grande parte delas sucumbiu às dificuldades naturais dos rios e às dificuldades de manutenção dos núcleos de povoamento e de criação de armazéns para a estocagem da produção, o que dependia muito mais das iniciativas particulares.

Apesar das inúmeras propostas, entre elas também a criação de um canal pelo Rio de São Mateus, o projeto do Rio Doce foi o que mais longe chegou, embora não tenha sido, em grande parte, bem sucedido. Parece que, no Brasil, com tantos canais fluviais, as estradas por terra sempre foram preferidas. Isso já era observado pelo governador de Espírito Santo, Antônio Pires da Silva Pontes, que tanto empenho tinha em abrir o canal do Rio Doce. Em carta ao governador de Minas Gerais, em 1803, ele expõe as vantagens de seu projeto:

Os conhecimentos extensos em vários ramos de literatura que adornam a muito ilustre pessoa de V. Exa me contém a pena para espaciar-me sobre matéria desse evidente entre os economistas políticos da preferência que têm os transportes

\footnotetext{
${ }^{16}$ BNL, seção de periódicos, Correio Braziliense, 1819, rolo 1739, fls. 59-63.
} 
por água aos da terra havendo só de restringir-me nas comodidades do Rio Doce. (...) fica sumamente proveitosa a navegação para a Barra do Rio Doce ou devem verificar em poucos dias os valores triplos e quádruplos dos seus gêneros, enquanto por terra se lhes faz impraticável exportar-lhes para o Rio de Janeiro, por preferirem os tropeiros de terra as fazendas mais próximas da Estrada Geral, quais são da Comarca do Rio das Mortes, providos dos mesmos gêneros. (...). Pelo que pertence porem a Comarca do Serro Frio, desta parece de absoluta necessidade aquela navegação (...) porque enquanto fazem meia viagem para o Rio de Janeiro na caravana ordinária das recovagens de terra se acham neste Porto, donde a recondução dos gêneros da Europa é muito mais fácil ${ }^{17}$.

Ele acrescenta que a comodidade e a tradição faziam com que os grandes negociantes persistissem em utilizar os caminhos terrestres e de manter comércio apenas com a Bahia, o Rio de Janeiro e os Campos dos Goitacazes, sendo que o Espírito Santo poderia oferecer peixes em grande quantidade por ser a "perene mina dessa terra"

Depois das inúmeras expedições o Rio Doce, é escolhido como a melhor proposta para interligar Minas ao Espírito Santo e ao mar. Segundo o Conde de Palma, o Comandante Antônio Rodrigues Taborda se destacou nos trabalhos de cultivo e povoamento das margens do Rio, o qual se beneficiou muito dos trabalhos precursores do Capitão de Fragata Antônio Pires da Silva Pontes, que realizou, em 1800, a carta com o primeiro levantamento do percurso desde a foz, no oceano, "até às cachoeiras das Escadinhas". O Conde de Palma considerava "pasmoso" o trabalho realizado em tão pouco tempo e que já contava, no ano de 1811, com um grande número de colonos e grande produção agrícola ${ }^{19}$.

\footnotetext{
${ }^{17}$ Seção Colonial 278, fl. 47v, APM. São várias as correspondências entre esses dois governadores, sendo que em uma delas algumas companhias de comércio da Bahia são mencionadas como interessadas na abertura dos canais fluviais como as Casas de Comércio: Gomes \& Mello e Cardoso \& Achiolli. SC 278, fl. 31, APM. Ver, também: ACC, Pl. 20247, rolo 527, APM.

${ }^{18}$ Seção Colonial 278, fl. 47v, APM.

${ }^{19}$ Biblioteca Nacional de Lisboa, Seção de periódicos, Correio Braziliense, 1811, rolo 1727, fl. 225-8.

"Notícias sobre os novos estabelecimentos do Rio Doce".
} 
Uma vez elaborado o plano de abertura do Rio Doce, através da criação de uma associação por Domingos Loureiro e outros comerciantes da Corte, ele foi submetido à apreciação da Junta do Comércio, Agricultura, Fábricas e Navegação em 1812. Entretanto, o pedido é indeferido por ser considerado restritivo e por "ofenderem aquela igualdade com que todos os concidadãos devem admitir-se as comodidades sociais" ${ }^{20}$. Esse pedido, entretanto, não é indeferido sem que seja feita uma minuciosa consulta ao Desembargador Fiscal da Junta. Com uma escrita rebuscada e sutilmente elaborada, ele vai descaracterizando a aparente "utilidade pública" de canal de comércio entre Minas e Espírito Santo. Inicialmente, ele compreende que, mesmo sendo maléficas "no presente e luminoso século", as companhias poderiam trazer alguns benefícios, como um veneno "disposto por mão mestra, proporcionado em doze própria e temperado com as preparações da arte tem servido de antídoto as mais graves enfermidades". Sendo a privação do comércio um veneno político, é lícito admiti-lo em determinadas circunstâncias, como tantos exemplos existiram num passado próximo da história de Portugal. Devido à ausência de estradas adequadas às terras centrais, a proposta da abertura do canal chegava a ser mesmo um "ofício de patriotismo". Observando-se, porém, de perto a proposta, o Desembargador começa a enumerar os problemas da pretendida companhia. Quanto ao fundo da companhia, ao número de seus acionistas, ao valor das ações, ao modo de aplicá-las, à duração da sociedade e à disposição de seus signatários, o Desembargador em nada se opõe, mas são inúmeras suas restrições quanto à parte orgânica e administrativa.

Em primeiro lugar, o artigo 14 propunha que, enquanto durasse a companhia, nenhuma outra poderia ser criada para que os lucros fossem garantidos e que a todo negociante, acionista ou não, fosse livre o comércio pelo canal do Rio Doce. Nos artigos 18 e 19, propunha-se criar condições para a agricultura, solicitando sesmarias para atrair colonos para a região. Nos artigos 20 e 24, pedia-se a isenção de todos os direitos de importação e exportação por um período de 20 anos. Em relação a este último, o

\footnotetext{
${ }^{20}$ JCAFN, fundo 7X, fl. 168v-178, Arquivo Nacional do Rio de Janeiro.
} 
Desembargador se assusta. Por estar o Estado do Brasil "na fundação de um novo império", não poderia ser desfalcado de nenhuma reserva. Nos artigos 38 e 39, solicitavase que os armazéns e demais mecanismos que fossem feitos para a manutenção e conservação do canal corressem por conta da Real Fazenda e de suas madeiras. Por último, pedia-se, no artigo 42, que toda a desobstrução da foz e cachoeiras do Rio Doce fosse feita pela Real Fazenda. Diante de todos esses itens, sai o veredicto:

Ainda que o plano tenha o importante objeto do novo comércio e navegação do Rio Doce, contudo a companhia não se encarrega de fazer as outras mais dispendiosas e essenciais a esse destino, como seriam a destruição das cachoeiras, as estradas de terra e as fortificações contra os botocudos. Antes requer que as faça a Real Fazenda, ou que esta lhes pague pela conta que devem. Além disso, pretendem exorbitantes privilégios, pelos tênues sacrifícios a que unicamente se comprometem de transporte gratuito de ilhas, de construção de embarcações, roubos e casas de arrecadação de mercadorias e de novas culturas de especiarias. Mas isto mesmo é fácil de se evadir na parte mais onerosa, e não se obrigam a coisa alguma, senão o cumprirem, ou o fizerem com utilidade não considerável ao público, ficando, entretanto, o país privado por vinte anos do gradual progresso do comércio, que os tempos findos, e interesses dos indivíduos poderiam ir introduzindo pela firmeza da nova legislação ${ }^{21}$.

A resposta do Desembargador é bastante lógica e propõe uma reflexão sobre a concessão de privilégios a particulares com ônus aos cofres públicos. Se o Estado deveria arcar com todos os custos da operação, porque ele entregaria a administração de tal empresa a um grupo privilegiado, que nada mais faria do que arrecadar os lucros? "Seria absurdo abandonar-lhes as rendas", conclui o Desembargador. Até mesmo o aparente "louvável" artigo sobre o transporte gratuito dos ilhéus é enganoso, pois previa o reembolso após o primeiro ano. Segundo o Desembargador, isto "reduziria aqueles miseráveis à quase servidão, visto que lhes seria depois difícil libertarem-se das dívidas". Outro efeito negativo seria o de povoar lugares ermos,

${ }^{21}$ JCAFN, fundo 7X, fl. 168v-178, Arquivo Nacional do Rio de Janeiro. 
despovoando outros, pois "são assaz experimentados na história das colônias os fatais efeitos de transportar a certos lugares ermos grande número de pessoas, ainda que industriosas e bem dirigidas", diz o Desembargador. Finalmente, sobre essa matéria, afirmava o consultor que a razão ensina que, nas novas colônias e nos arroteamentos de terras virgens, produzia-se primeiro para a subsistência, e, somente quando a produção era excessiva poderia ser comercializada, não sendo conveniente a proposta de uma imediata cultura exportável de especiarias nas novas sesmarias ${ }^{22}$.

Não obstante a primeira negativa, os negociantes estabelecidos no sertão do Rio Doce voltam a apresentar o projeto em 1819. Eles alegavam que não era possível haver um só capitalista que tanto se arriscasse para empreender a abertura do canal que a todos beneficiaria. Acrescentavam que não pretendiam nenhum monopólio e que, além disso, seria da maior utilidade para o Estado por sua arrecadação. A sociedade a que se propunham previa a entrada de acionistas com seus devidos capitais, que, "no caso não esperado de falirem as operações da sociedade", correriam apenas o risco correspondente às suas entradas ${ }^{23}$. Diziam que muitos capitalistas, negociantes, proprietários e lavradores da província do Rio de Janeiro e de Minas Gerais iriam concorrer com suas assinaturas, contando que seria esse plano da real aprovação do Rei. Esperavam que a subscrição passasse de seiscentos contos de réis somente nas duas províncias, além dos pretendentes do Espírito Santo ${ }^{24}$.

Com base nesse novo pedido, em 18 de março de 1819, foi criado o estatuto da Sociedade de Agricultura, Comércio e Navegação do Rio Doce ${ }^{25}$, mas sua execução não foi simples. A proposta, em forma de estatuto, foi, novamente, enviada à Junta do Comércio, Agricultura, Fábricas e Navegação por Francisco Joaquim da Silva, solicitando a real confirmação para o empreendimento. Em resposta ao requerimento, o Deputado José Pereira Fonseca informava ao Presidente da Junta que não

\footnotetext{
${ }^{22}$ JCAFN, fundo 7X, fl. 168v-178, Arquivo Nacional do Rio de Janeiro.

${ }^{23} \mathrm{ACC}$, rolo 527, APM.

${ }^{24}$ ACC, rolo 527, APM.

${ }^{25}$ ACC, rolo 527, APM.
} 
encontrava nos estatutos nada que ofendesse "os bons princípios de economia pública, à exceção do artigo 16 em que se declara que as entradas dos acionistas, que se tiverem realizado nos cofres da sociedade, serão isentos de penhora e execuções ainda mesmo fiscais" ${ }^{26}$. Apenas os credores teriam direito aos dividendos, enquanto durasse a sociedade, segundo o mesmo artigo. Para o referido Deputado, parecia um incentivo aos maus pagadores e aos devedores de má fé, sendo, ainda, contrário ao direito da propriedade pública. Elogia, contudo, o grande benefício que se poderia retirar de uma tal empreitada, principalmente para os produtores e comerciantes das Comarcas de Vila Rica, Serro Frio e Sabará, mas não acreditava que ela pudesse se realizar em curto espaço de tempo, mesmo porque exigiria muito tempo, capital e mão-de-obra. Além disso, seria um negócio extremamente arriscado, e os acionistas poderiam alcançar maiores benefícios se aplicassem seu dinheiro no Banco Nacional, em Companhias de Seguro ou letras de câmbio.

Conclui, portanto: "Não duvido da importância dos fins, mas desconfio da eficácia dos meios. Como, porém, o dito plano e seus estatutos não contêm monopólios e privilégios exclusivos, nem condições onerosas ao público, parece-me estar no caso de merecer a real aprovação" ". Assim sendo, o estatuto é aprovado em 19 de outubro de 1819. Entretanto, em tudo o que está exposto no estatuto da Sociedade, ele em nada diferia do primeiro pedido, sendo "mascarado" em alguns pontos, mas conservando o caráter de monopólio e privilégio.

O final do século XVIII e, principalmente, o início do século XIX assistem à intensa procura pelo conhecimento do território brasileiro, sobretudo no sentido de se conhecer os caminhos, terrestres ou fluviais que pudessem interligar as distantes regiões e suas diversas produções. Interiorização, povoamento, investimentos na produção e integração dos territórios são os argumentos recorrentes das expedições militares que se iniciam pelo Brasil durante esse período, mesmo que subjacente a

${ }^{26}$ JCAFN, fundo 7X, fl. 178v-180, Arquivo Nacional do Rio de Janeiro.

${ }^{27}$ Idem. 
esse discurso estivesse presente o desejo de encontrar novas fontes de riquezas minerais. A principal tarefa era assinalar as rotas mais importantes, desenhar mapas e tentar mensurar a população e as produções para traçar planos de organização e integração dessas regiões.

Um bom exemplo desse trabalho é o quadro estatístico da Capitania de Goiás, de 1804 a 1806, seguido das Reflexões econômicas sobre as tabelas estatísticas da Capitania, elaboradas a partir dos dados coletados pelas Câmaras Municipais ${ }^{28}$. As reflexões têm início com a ponderação de ser Goiás “a mais ocidental das capitanias do Brasil” e de ser seu comércio com o Rio de Janeiro, São Paulo e Bahia todo feito por terra.

Este extenso país seria talvez até hoje desconhecido se o desejo de achar novas minas não tivera motivado o seu descobrimento (...). Divide-se em duas repartições: o norte e o sul, que pela extensão de seu território podem formar duas comarcas: em ambas são auríferas as suas terras, e produzem o quanto é necessário para os seus habitantes, para as comodidades de uma vida frugal e abundante. Milho, feijão, cana de açúcar, mandioca, arroz, gados e algodão, são artigos principais de sua produção. A vinha renova o seu fruto duas vezes por ano; o trigo vem em algumas paragens, mas ela carece pela maior falta de salinas ${ }^{29}$.

Apesar disso, o autor das Reflexões garantia que a Capitania estava pobre, sendo seu comércio apenas passivo, isto é, pouco exportava e importava grande parte do que necessitavam.

Muitos dos gêneros que lhe vem dos portos de mar como o ferro, aço, cobre, chumbo, pólvora, baeta, baetões, panos e louças, sendo de grande peso e volume, o transporte os torna caríssimos, e desta maneira, o ouro que produzem as lavras, não chega para pagar os gêneros de necessidade e de luxo. (...). § A sua população está

\footnotetext{
${ }^{28}$ AHU, Códice 2109, Reflexões econômicas sobre as tabelas da Capitania de Goiás em m1804 e feitas em 1806". (todo o códice). Lisboa.

${ }^{29}$ AHU, Códice 2109, Reflexões econômicas sobre as tabelas da Capitania de Goiás em m1804e feitas em 1806”. (todo o códice). Lisboa.
} 
em grande desproporção com o seu território. Que causas têm obstado o seu aumento? Para conhecê-las é necessário considerar esse objeto em relação aos habitantes e aos meios que eles tem tido para se estabelecerem e produzirem ${ }^{30}$.

A partir deste ponto, o autor começa a analisar a natureza dos povos que colonizaram a região. Para ele, índios, europeus e africanos constituíam o núcleo da povoação de Goiás e cada uma dessas raças tinha razões para não se integrar e desenvolver o território. Os índios não tendo sido bem tratados ou sendo mesmo dizimados não teriam nenhuma razão para produzir, principalmente se não ficassem com o fruto da produção. Os europeus, por sua vez, só se interessavam pela mineração e ganhos fáceis e rápidos, não investiam em agricultura. Os negros, segundo o texto, tinham sido introduzidos numa razão de masculinidade desproporcional, não deixando, depois do auge minerador, que esta população se reproduzisse o suficiente para fazer florescer a agricultura.

Para o autor das Reflexões, não seria apenas necessário aumentar o número da população, se não fosse "aumentada" também no sentido político, isto é, seguindo o pensamento da economia política dominante na época, seria necessário criar ocupações para todas as classes para que cada pessoa empregada criasse um novo valor através de seu trabalho, o que antes não existia.

Pensou-se por muito tempo que nestas capitanias não devia haver mais que agricultores, comerciantes e mineiros, que o ouro extraído sobejaria para pagar os objetos de consumo, o valor dos negros, instrumentos da mineração e lavoura, bem como o de tantos artigos de necessidade e de luxo, indispensáveis a um povo que não tinha alguma sorte de manufaturas (...). § Obstar ao estabelecimento das manufaturas nas colônias tem sido a máxima constantemente seguida pela política européia. Aquelas não se fundaram não se alimentaram nem se defendem sem despesa de gentes e cabedais. O reconhecimento exige delas um tributo que devem pagar às fábricas e ao comércio da pátria mãe. Se lhes fora permitida indefinidamente toda a sorte de indústrias, breve seriam independentes e os

\footnotetext{
${ }^{30}$ Idem.
} 
governos atraiçoariam os mais sólidos interesses da nação, se não fossem vigilantes sobre tão importante objeto. Mas esta regra não poderá modificar-se? ${ }^{3}$

O autor irá ponderar sobre a necessidade das colônias produzirem suas próprias manufaturas, principalmente, estando a uma distância muito grande dos portos do mar. Compara a Capitania de Goiás com a de Minas Gerais, a qual estava a 80 léguas do Rio de Janeiro e se havia encontrado em situação semelhante à de Goiás em seu áuge minerador. Devido às circunstâncias da decadência aurífera e da grande produção mineira de muares, algodão, couro, sola, queijo, marmelada, carne de porco, boiada, etc., além da fabricação de todos os tecidos em lã, algodão, chapéu, e louça, Minas conseguia exportar sua produção, mesmo sendo proibidas as manufaturas. Essa "regalia" era atribuída à "conivência dos governos" e não a uma autorização ministerial, segundo o autor.

Se as condições de Goiás eram as piores, somente com a existência de empreendedores e a criação de uma companhia de negociantes seria possível vencer as barreiras naturais da Capitania. Isso dependeria de abertura de canais, estradas e, claro, o investimento de grandes cabedais.

Negociantes pobres, cujos fundos são principalmente o seu crédito, como os desta Capitania não podem entrar por si sós em especulações arriscadas nem animar os agricultores com o pagamento efetivo das suas produções e antecipar-lhes dinheiro por conta, como é muitas vezes necessário. Como será que eles estabelecerão as feitorias indispensáveis num país despovoado e de gentio na maior parte de sua extensão? É certo que os governos deverão dar o princípio a essas povoações, facilitar o seu estabelecimento por isenções e privilégios, bem como guarnece-las de tropas, mas por conta do público não podem ocorrer provisões necessárias para os navegantes, nem as providências necessárias para os navegantes, nem as providências em caso de naufrágio, moléstias, e outros acidentes ${ }^{32}$.

\footnotetext{
${ }^{31}$ AHU, Códice 2109, Reflexões econômicas sobre as tabelas da Capitania de Goiás em 1804 e feitas em 1806”. (todo o códice). Lisboa.

${ }^{32}$ AHU, Códice 2109, Reflexões econômicas sobre as tabelas da Capitania de Goiás em m1804 e feitas em 1806”. (todo o códice). Lisboa.
} 
A conclusão do autor é que era urgente e necessária a presença do poder do Estado para promover o desenvolvimento econômico da região, pois todo o empreendimento não poderia ficar a cargo de particulares, sendo de grande utilidade privilégios, redução de preços e doações de terrenos para incrementar a agricultura, a manufatura e o comércio de Goiás ${ }^{33}$.

No ano de 1811, é aprovado, através de carta régia, o Plano de estabelecimento de uma sociedade de comércio para a Capitania de Goiás e do Pará, concedendo privilégios aos acionistas, "civilizando" os índios das nações Canajá, Apinagê, Chavante, Cherente e Canoeiro. Do mesmo modo, abria-se a navegação dos rios Tocantins e Maranhão, além de venderem casas a 240 réis. Essa atitude é comemorada pelo correspondente do Correio Braziliense, Hipólito José da Costa. Ele afirma que, mesmo com alguns inconvenientes, a providência era louvável.

Persuadidos como nós estamos de que o comércio externo do Brasil não pode ter bases mais seguras do que o mesmo comércio interno daquele país; e que os inumeráveis rios que banham aquele fértil território, oferecem as maiores facilidades à exportação dos produtos do interior. Não podemos deixar de alegrarnos com todas as medidas tendentes a estes fins. ${ }^{34}$

Os únicos reparos feitos por Hipólito às providências que vinham sendo tomadas tanto pela Coroa quanto pelos brasileiros eram: a má escolha da sede do Governo e a falta de incentivo ao aumento da população. Quanto à primeira questão, Hipólito diz que o Rio de Janeiro não possuía nenhuma qualidade para ser sede do Império do Brasil, pois o ideal seriam as terras centrais, próximas aos maiores e principais rios.

\footnotetext{
${ }^{33}$ Segundo dados estatísticos dos mapas anexos às Reflexões, Goiás contava com uma população total de 50.365, sendo 14.084 homens livres, 16.254 mulheres livres, 12.094, escravos e 7.933 escravas. Chama a atenção o maior número de mulheres livres em relação à população masculina e, também, a maior diferença numérica entre os escravos, como é enfatizado no próprio documento. AHU, Códice 2109, Reflexões econômicas sobre as tabelas da Capitania de Goiás em m1804 e feitas em 1806". (todo o códice). Lisboa.

${ }^{34}$ Biblioteca Nacional de Lisboa, Seção de periódicos, Correio Braziliense, 1813, rolo 1729, fl.374.
} 
Edificariam ali uma nova cidade, começariam por abrir estradas que se dirigissem a todos os portos do mar e removeriam os obstáculos naturais que tem os diferentes rios navegáveis, laçariam assim os fundamentos ao mais extenso, ligado, bem defendido e poderoso império, que é possível que exista na superfície do globo, no estado atual das nações que o povoam (itálicos meus) ${ }^{35}$.

Hipólito da Costa diz que a escolha do Rio de Janeiro para sede só aconteceu porque lá já havia algumas habitações, passagens para carruagens, um "mesquinho" teatro e cantoneiras. Apenas isso serviu de pretexto para evitar "o trabalho de criar uma cidade de novo", a qual poderia ter o nome do Príncipe Regente, imortalizandoo "na criação de uma vasta monarquia". Hipólito achava que o Rio de Janeiro era muito próprio para o comércio, mas inadequado para ser a sede administrativa do território, o qual se encontrava quase incomunicável entre suas partes. Isto, segundo o autor, não era inviável, pois os Estados Unidos havia edificado sua sede onde não existia uma só casa e isso era "um argumento tirado da experiência de nossos tempos que nada pode contradizer”. A segunda questão apresentada por Hipólito dizia respeito a entrada de estrangeiros no Brasil, os quais deveriam ser atraídos para constituir uma maior população e "mais conveniente", mas não deveriam ter nenhum convite especial, pois deveriam vir com o espírito para trabalhar e aqui construírem seus lares e nação. Para ele, o Brasil tinha entre seus únicos estrangeiros a "pior sorte de população", que eram os negociantes, pois eles vinham apenas com o intuito de se enriquecer e logo ir embora: "Durante a sua residência temporária, conformase por prudência, com os usos estabelecidos, sejam bons, sejam maus, tira todo o partido que pode (...); e faz o que ele chama o seu ofício, que é comprar por menos e vender por mais". Como as devidas providências não são tomadas, Hipólito é des-

\footnotetext{
${ }^{35}$ Idem. Uma nova defesa de uma capital central no Brasil aparece novamente no ano de 1816, v. 17 do Correio Braziliense. Para tal empreitada, Hipólito da Costa diz que o governo deveria empregar mendigos e soldados licenciados, além de pagar a trabalhadores e cobrar "pedágios" dos viajantes. Essa obra, consequientemente, povoaria as margens dos rios próximas aos destacamentos e trabalhadores, par os quais deveriam ser oferecidas pequenas datas de terra para o cultivo. BNL, rolo 1735, fls. 95-8.
} 
crente em relação à administração do Brasil e seu futuro, já que seus ministros eram "comparáveis ao barqueiro que conduz o barco segundo a corrente da maré, movendo unicamente o leme com quase nenhum trabalho, e ainda assim encahaca (sic) seu vaso ao menor encontro de uma revessa inesperada" ${ }^{36}$.

Apesar de todo o ceticismo do correspondente do Correio Braziliense em relação aos males administrativos do Brasil, ele sempre publicava e comentava entusiasmado os "Melhoramentos no Brazil", sobretudo no que dizia respeito ao processo de interiorização. Assim é com a publicação de um "extrato" da Gazeta do Rio de Janeiro de 1811, que faz uma síntese dos progressos das expedições para a abertura da navegação interior. A Vila de Cuiabá, Comarca de Mato Grosso, é o ponto de partida para o conhecimento dos rios Madeira, Amazonas, Pará, Arinos, Tapajós em direção ao norte, como dos rios Cuiabá, São Lourenço, Tucariu, Paraná e Tietê em direção a São Paulo $^{37}$. Isto significava uma nova forma de comunicação de São Paulo com o Pará e de integração de todas as partes do vasto território em seu comércio interno.

Não só os rios, mas também as estradas e pontes completavam os investimentos na ligação entre as diversas capitanias e suas vilas. Esse é o caso do novo caminho que se abria de Campos dos Goitacazes para as Minas no ano de 1817, passando pelo registro do Rio Pomba, próximo a foz do Rio Paraíba. Neste caminho, 18 pontes foram construídas de São Salvador até São Fidélis e, de São Fidélis até o Rio Pomba, mais 12 pontes. Em artigo, de autor anônimo, encaminhado ao Correio Braziliense, podemos ver todo o otimismo daquele tempo: "Hoje tem raiado um novo sol para aqueles horizontes, borbulham já novas fontes de riquezas; cresceu a indústria e os trabalhos rurais florescem consideravelmente, estão comunicadas as províncias circunvizinhas e a parte central recebeu o novo e maravilhoso impulso" ${ }^{38}$.

\footnotetext{
${ }^{36}$ Biblioteca Nacional de Lisboa, Seção de periódicos, Correio Braziliense, 1813, rolo 1729, fl.374.

${ }^{37}$ Capistrano de Abreu (1960: 83) diz que, desde que se erigiu a Capitania de Mato Grosso, não restava outro recurso senão utilizar os rios Madeira e Marmoré como vias de comunicação com o Pará, apesar dos seus "colossais embaraços oferecidos pelos trechos encachoeirados". Para o autor, essas vias e novos caminhos concluíram a obra "antipaulística", pois fora iniciada nos "morticínios dos pantanais".

${ }^{38}$ Biblioteca Nacional de Lisboa, Seção de periódicos, Correio Braziliense, 1820, rolo 1739, fl. 396.
} 
Capistrano de Abreu, ao estudar os caminhos antigos e povoação do Brasil, conclui que podemos resumir o povoamento de nossa terra a algumas linhas principais, "como num país as águas se somam em algumas bacias preponderantes" (Abreu1960: 129). São quatro os movimentos de povoamento no Brasil, segundo Capistrano: um que se inicia na Capitania de São Vicente (São Paulo) em direção ao Sul e ao Centro-oeste; um segundo movimento que parte da Bahia e segue toda a extensão do Rio São Francisco e norte de Minas Gerais; o terceiro é o movimento de Pernambuco, mais modesto e que segue em direção ao norte da Capitania; o último movimento é da Capitania de Maranhão, que se uniu à Bahia e Pernambuco, inicialmente, para depois seguir em direção ao Tocantins e Pará. Para Capistrano, esses quatro movimentos encerravam todos os esforços de comunicação que foram empreendidos no Brasil até o início do século XIX. "Assim no princípio do século último estava todo o país ligado, imperfeitamente embora, por meio de vias terrestres ou fluviais. Chegar-se-ia a formar um conjunto, uma nacionalidade? O sistema colonial era a divergência, o particularismo; o centro ficava além-mar" (Abreu 1960:133). Segundo Capistrano, a chegada da Corte tornou intrínseco o centro que estava fora. E até o final do primeiro reinado se completara a obra de convergência das partes que, "apesar das revoluções profundas realizadas" durante este período, "tudo se pautou por uma evolução gradual e legítima" que cimentou a obra nacional.

A transferência da Corte para o Rio de Janeiro tornou a cidade a sede do governo que, segundo Capistrano, deveria estabelecer-se, por merecimento, em São Paulo, Pernambuco ou na Bahia, que "rasgaram a cintura das matas ambientes". Mas coube ao Rio de Janeiro se transformar na cabeça da nação, embora não tenha sido o ponto de partida da primeira idéia de nação, foi onde se realizou o sonho, "que bem perto esteve de esvair-se como sonho" (Abreu 1960: 134).

Estradas e abertura de navegação, assim como a redução de impostos e emissão de moeda, estavam na ordem das reformas propostas para dinamizar as produções internas da colônia a partir de fins do século XVIII. O ano de 1808 representou um momento de incentivo às produções coloniais, agropecuárias e manufatureiras e da abolição de monopólios régios e restrições. Mesmo que todos os esforços ou 
providências não tenham resultado um constante e irreversível progresso econômico para o Brasil, pelo menos representaram uma primeira tentativa de integração territorial por meio do conhecimento estatístico da população, da produção e do conhecimento das terras "centrais" e de suas possibilidades de comunicação.

A partir do que foi dito, torna-se claro que uma nova percepção sobre o espaço se constituía na América portuguesa, sede temporária do Império luso, e embrião do Estado imperial brasileiro. Para Isván Jancsó (1996: 8), os amplos projetos reformistas desdobraram-se em movimentos complementares e contraditórios: um administrativo-militar e outro econômico-mercantil. Esse processo, segundo o autor, baseou-se na busca da racionalização através da intervenção do poder central no fomento, controle e distribuição da atividade produtiva. Efetivamente esse controle e racionalização operaram-se através da produção de conhecimento quantitativo e qualitativo sobre o conjunto a ser governado.

\section{Referências Bibliográficas}

ABREU, Capistrano de. Caminhos antigos e povoamento do Brasil. $2^{\mathrm{a}}$ ed. São Paulo: Livraria Briguiet, 1960.

BARBOSA, Waldemar de Almeida. Dicionário histórico e geográfico de Minas Gerais. Belo Horizonte: Saterb, 1971.

BRITO, Francisco T. de. Itinerário Geográfico. In: Revista Barroco. Belo Horizonte:UFMG, n.4, 1972.

DESCRIPÇÃO geographica, topographica, historica e politica da Capitania de Minas Geraes. Revista do Instituto Histórico e gegráfico Brasileiro. Rio de Janeiro: Imprensa Nacional, v.71, pp. 117-94, 1908.

FRADE, P. Estatistica Chorographica de Distancias do Estado de Minas Geraes. Belo

Horizonte: Imprensa Oficial, 1906.

GOULART, José A. Tropas e tropeiros na formação do Brasil. Rio de Janeiro: Conquista, 1961. .Meios e instrumentos de transporte no interior do Brasil. Rio de Janeiro: MEC, s.d.

HERRENSCHWAND, M. Discurso Fundamental sobre a população - Economia política moderna (1786). Rio de Janeiro: Imprensa Régia, 1814. 
HOLANDA, Sérgio B. Caminhos e Fronteiras. Rio de Janeiro: José Olympio, 1957.

JANCSÓ, Isván. “A construção dos Estados Nacionais na América Latina”. In: SZMRECSÁNYI, Tamás. História econômica do período colonial. São Paulo: Hucitec, 1996.

RIZZINI, Carlos. Hipólito da Costa e o Correio Braziliense. São Paulo: Ed, Nacional, 1957. ROCHA, Antônio Penalves. A economia política na sociedade escravista. São Paulo: Hucitec, 1996. 